\title{
Synthesis and Crystal Structures of Transition Metal Ion Complexes of Di(2- thienyl)imide
}

\author{
Ting Jiang, Tejal K. Naik, Cynthia S. Day, Ronald E. Noftle* \\ Department of Chemistry, Wake Forest University, Winston-Salem, NC 27109 USA \\ *corresponding author
}

Keywords: di(2-thienyl)imide; metal complexes; crystal structures; polymer; metal ion uptake and release

\begin{abstract}
Di(2-thienyl)imide, $\mathbf{1}$, has been shown to chemically polymerize, and, if metal complexes of 1 could be synthesized, the polymer could have potential applications as an ion sensor and environmental remediation agent. As a first step towards this goal, di(2thienyl)imide is shown to form complexes with $\mathrm{Mn}$ (II), Co (II), and $\mathrm{Zn}$ (II) perchlorates. The complexes of $\mathrm{Mn}^{2+}$ and $\mathrm{Co}^{2+}$ are isostructural with two di(2-thienyl)imide ligands in equatorial positions and two perchlorate ions axial. The $\mathrm{Zn}^{2+}$ complex has two water molecules in the axial positions and the thiophene rings in the two equatorial ligands are tilted in the same direction from the median plane due to intra- and intermolecular contacts. The crystal structures and infrared spectra, as well as an improved synthesis and polymerization of di(2-thienyl)imide, are reported and discussed.
\end{abstract}

\section{Introduction}

Di(2-thienyl)imide, 1, was recently prepared [1] in low yield and attempts were made to polymerize this monomer electrochemically. No polymerization occurred unless a large amount of catalytic bithiophene was added to the electrolyte; the copolymer that formed contained about $12 \%$ of $\mathbf{1}$. If metal ions bind to the polymer via the imide function, the material could have applications as a metal ion sensor and an environmental remediation agent by virtue of electrochemically controlled uptake and release (Scheme 1). Although many coordinating groups have been attached to conducting polymers as agents to bind metal ions in metal ion sensor applications as detailed in a recent review $[2,3]$, fewer systems involving a coordinating group as part of the thiophene conducting polymer backbone itself have been reported [3-7]. A pertinent example involves the imide analog, 1,3-propanedione, in the thiophene chain which optical evidence indicates does bind metal ions by anionic-cationic interaction [8]. Other related materials are an alt-pyridine-imide oligomer [9] and imide-urea structures [10] which were synthesized for their hydrogen bonding capabilities; however, coordination with metal ions was not investigated. A number of polymers containing $\mathrm{N}$-substituted cyclic imides has been prepared but these do not have metal-ion binding capability through the imide function [11]. A system involving the use of overoxidized polypyrrole, containing pendant carboxylate and sulfonate substituents, has been used as a solid-phase extraction media [12]. Electrochemical switching was employed to extract and desorb selected alkaline earth metal ions as well as $\mathrm{Ni}^{2+}$ and $\mathrm{Cd}^{2+}[12]$. Polypyrrole has been used to remove heavy metal ions from wastewater by a counterion effect which releases the ions on 
electrochemical reversal [13]. Therefore it was of interest to attempt preparation and characterization of metal complexes of the di(2-thienyl)imide monomer to demonstrate that our approach to these applications was feasible and to improve the yield and the polymerization process. In this paper, we report three new metal ion complexes composed of $\mathrm{Zn}(\mathrm{II}), \mathrm{Mn}(\mathrm{II})$, and $\mathrm{Co}(\mathrm{II})$ perchlorates and neutral di(2-thienyl)imide bonded only through the carbonyl-oxygen atoms. A review of related literature revealed a number of structures of complexes containing neutral dialkylimides bonded through the carbonyl-oxygen atoms [14-16] as well as lanthanide complexes of neutral carbacylamidophosphates, which are imide analogues containing a phosphoryl group, bonded via carbonyl and phosphoryl oxygen atoms [17]. However, only one report of a neutral arylalkylimide similarly bonded was noted [18], and to the best of our knowledge there are no structures of complexes involving neutral diarylimides. Some examples of deprotonated diaryl imides are known with benzoylbenzamide [19] and in catena complexes bonded through oxygen to the central metal ion, but always in conjunction with bonding to the terminal or central metal ions via the nitrogen atom of the deprotonated imide [20]. For our purposes, relatively weak coordination is preferable such that metal ions can easily be released; therefore neutral oxygen donors are preferred to nitrogen donors or anionic imides which bind more strongly. The crystal structures, infrared and visible spectra, and analytical data of these new complexes are presented and discussed. We also report an improved yield of di(2-thienyl)imide, and a method of polymerization.

\section{(Insert Scheme 1 here)}

\section{Results and Discussion}

\subsection{Synthesis}

\subsubsection{Di(2-thienyl)imide and Poly(di(2-thienyl)imide}

Di(2-thienyl)imide, 1, was prepared as described earlier by the reaction of 2thenoyl chloride with 2-thiophene carboxamide using potassium t-butoxide as a catalyst. The yield from this reaction is low (12\%) and separation of the product by column chromatography is tedious. Using a few drops of conc. $\mathrm{H}_{2} \mathrm{SO}_{4}$ as catalyst instead increased the yield slightly. Microwave-assisted synthesis (acid catalyst) using a procedure modified from that of Lee, et al. [21], optimized for power and time, increased the yield to $18 \%$. Infrared, mass, and ${ }^{1} \mathrm{H}$ NMR spectra were consistent with the published data [1]. In another attempt, using potassium hydride as a base to facilitate attack of the carbonyl group on the amide function, the yield was only slightly increased over that using the base, potassium t-butoxide (13.4\%). With lithium hydride, another product formed which eluted with an $\mathrm{R}_{\mathrm{f}}$ value so similar to that of $\mathbf{1}$ that analytically pure samples were not obtained even with different solvent mixtures.

Compound 1 does not polymerize electrochemically owing to the electronwithdrawing power of the imide function which requires a high potential and renders the cation radical very reactive. Bithiophene has been used as an electropolymerization catalyst [22], and, in our previous work [1], it was found that a large amount of 
bithiophene added to the polymerization mixture gave a copolymer which was mostly bithiophene but contained about $12 \%$ of 1. In this work, it was observed that polymerization of $\mathbf{1}$ could be achieved using ammonium peroxydisulfate which has been successful as an oxidant for polymerization [23]; however, the process of polymer formation took days and resulted in the formation of small flakes of polymer suspended in the aqueous reaction mixture. The conductivity indicated by EIS measurements was very low but the electrical properties should be improved by polymerization using Stille coupling rather than an oxidative process.

\section{(Insert Scheme 2 here)}

\subsubsection{Complexes of 1 with metal ions}

The procedure was similar for each of the complexes and led to the formation of good single crystals. In general, a warm solution of the ligand was added to a similar solution of the metal perchlorate and allowed to stand quietly, whereupon small crystals of the complex precipitated and were allowed to stand undisturbed for five days during which larger crystals formed.

\section{(Insert Table 1 here)}

\subsection{Crystal structures}

\subsubsection{Diaquabis(di(2-thienyl)imide)zinc(II) perchlorate, 2}

Complex 2 (fig. 1) is monoclinic, C2/c (\#15) with two bidentate ligands bonded equatorially through the carbonyl-oxygen atoms having "bite" angles of $84.39(5)^{\circ}$ with the thiophene rings syn to each other. The zinc ion and axially coordinated water oxygen atoms lie along the crystallographic two-fold axis. The charge on the $\mathrm{Zn}$ ion is compensated by two perchlorate ions. As in $\mathbf{3}$ and $\mathbf{4}$ (see below), the $\mathrm{C}=\mathrm{O}$ bonds (1.236(2) and 1.234(2) $\AA$ ) are lengthened relative to the free ligand consistent with coordination of the metal ion by oxygen. The $\mathrm{C} 1-\mathrm{N}$ and $\mathrm{C} 2-\mathrm{N}$ bonds (1.381(3) and $1.375(3) \AA$ ) are shortened consistent with a greater degree of delocalization over the -O$\mathrm{C}-\mathrm{N}-\mathrm{C}-\mathrm{O}-\mathrm{system}$. The $\mathrm{C}-\mathrm{C}$ bonds between the carbonyl carbon atom and the carbon on the thiophene ring (C1-C3 and C2-C7) are also shortened (1.448(3) and 1.452(3) $\AA$ ) indicative of some extended resonance over the $\mathrm{C}-\mathrm{C}$ bond in the complex. The di(2thienyl)imide ligand is distorted from planarity and the angle between the two 5membered thiophene rings is $18.1(1)^{\circ}$. The thiophene rings are tilted in the same direction from the imide plane by $18.80(8)^{\circ}$ and $14.11(8)^{\circ}$, respectively. The distortion from planarity results from close "intramolecular" contacts involving the imide hydrogen with the carbon and hydrogen atoms of the thiophene rings and short "intermolecular" thiophene S...thiophene H (2.81 $\AA$ and $2.91 \AA$, compared to the vdW distance, $3.00 \AA)$ [24] and thiophene...perchlorate ion contacts. The protons from the apical water molecules form hydrogen-bonds with perchlorate ions so that each perchlorate forms hydrogen bonds to waters on cations translated along the $b$ axis. As a result, pairs of perchlorate ions form 1-D chains of cations linked by perchlorates. The coordinated 
water molecules are not eclipsed but twisted about the 2 -fold axis by $52^{\circ}$ with respect to each other. Figure 1 shows the 1-D chains parallel to [010] which results in the formation of a layered arrangement of zig-zag thiophene rings alternating with layers of $\mathrm{Zn}$ and perchlorate ions, parallel to the $\left(\begin{array}{lll}1 & 0 & -1\end{array}\right)$ plane in the unit cell.

\section{(Insert Fig. 1 here)}

\subsubsection{Bis(di(2-thienyl)imide)manganese(II) perchlorate, 3, and bis(di(2- thienyl)imide)cobalt(II) perchlorate, 4.}

Since $\mathbf{3}$ and $\mathbf{4}$ are isostructural (fig. 2a), the discussion and figures will be in terms of $\mathbf{3}$. Complex 3 crystallizes in the monoclinic system, space group $\mathrm{P} 2{ }_{1} / \mathrm{c}$ (\#14). The two bidentate ligands are in the equatorial positions bonded to the metal ion through oxygen atoms and the thiophene rings in each ligand are syn to each other. The metal ion lies on the crystallographic inversion center. The ligand "bite" angles are $80.63(5)^{\circ}$; these are significantly smaller than those found for diaquabis(methyl-2-thienylimide)nickel (II) perchlorate $\left(86.90(6)^{\circ}\right.$ and $\left.86.18(6)^{\circ}\right)$ [18]. The nitrogen atom remains protonated and the charge on the metal ion is compensated by two inversion-related perchlorate ions bound at $180^{\circ}$ to each other in the apical positions. The structure of $\mathbf{3}$ is centrosymmetric with the mean planes of the two thiophene rings in each ligand tilted by $17.58(9)^{\circ}$ and 17.32(9) ${ }^{\mathrm{O}}$ from the mean plane of the $\mathrm{Mn}$ and four coordinated oxygens. The plane of the di(2-thienyl)imide ligand is bent by $14.32(7)^{\circ}$ from the metal coordination plane. Close contacts between an oxygen atom (O6) of the coordinated perchlorate ion with $\mathrm{C} 2$ and O2 (carbonyl group associated with one thiophene ring of the ligand) (fig. 2b) appear to result in tilting the mean plane of the thiophene rings from the mean plane of the oxygen atoms bound to the metal. Since the bound perchlorate is not symmetrically distributed across the mean plane (defined by the five- atom grouping $\mathrm{Cl1}, \mathrm{O} 3, \mathrm{M}$ ion, $\mathrm{Cl1}^{\prime}$, and $\mathrm{O}^{\prime}$ ), the remaining oxygens on the perchlorate ion do not make similar close contacts with $\mathrm{C} 1$ and $\mathrm{O} 1$ of the carbonyl group in the other thiophene ring of the ligand. However the symmetry-related perchlorate ion in the other apical position forms the same close contacts with the carbonyl group in the second ligand tilting the ligand in the opposite direction from the first. The N1-H...O4 distance (3.301(2) $\AA$ ) is larger than the van der Waal's sum $\left(\sim 3.1 \AA\right.$ for N...O) with an angle of $142(-)^{\circ}$ subtended at the hydrogen, indicating a very weak contact consistent with the sterically protected $\mathrm{NH}$ group. The bond length changes upon complexation are similar to those in 2 . The $\mathrm{C}=\mathrm{O}$ bond distances are both 1.235(2) $\AA$ compared to 1.207(2) and 1.217(2) $\AA$ in $\mathbf{1}$ [1]. The C-N

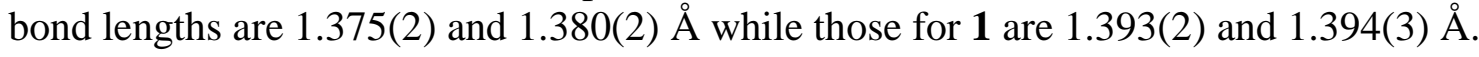
The carbonyl-carbon to thiophene-carbon distances (C1-C3 and C2-C7) decrease from 1.463(3) and 1.475(3) $\AA$ to 1.451(2) and 1.448(2) A compared to 1. Comparison of the carbonyl bond length changes can also be made with the free ligand dibenzamide [25] for which the $\mathrm{C}=\mathrm{O}$ bond distances are 1.219(3) $\AA$. A three metal ion catena complex [20] containing deprotonated dibenzamide ligands has been reported. Two of these ligands are bound to the central $\mathrm{Fe}^{\mathrm{II}}$ ion by four carbonyl oxygen atoms in which the $\mathrm{C}=\mathrm{O}$ bond distances are 1.236(2) and 1.239(2) ̊̊ showing a similar bond lengthening upon complexation. Dibenzamide shows bond lengths similar to those for $\mathbf{1}$ for $\mathrm{C}-\mathrm{N}$

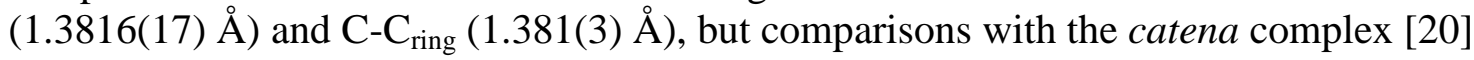


are not possible for these distances owing to the involvement of nitrogen in the bonding to the first and third $\mathrm{Fe}^{\mathrm{III}}$ ions.

The packing for 3 (and isostructural 4), shown in fig. 3, is a 1D network along the [010] direction resulting from a weak hydrogen interaction involving the perchlorate ion with the imide hydrogen of the di(2-thienyl)imide translated along the $\mathrm{b}$ axis.

(Insert Table 2 and Figs 2 and 3 here)

\subsection{Infrared spectra}

The FT-IR spectrum of di(2-thienyl)imide shows an N-H stretching band at 3419 $\mathrm{cm}^{-1}$ which is consistent with the absence of hydrogen-bonding [1], and the spectra of the metal complexes show similar frequencies $\left(3410-3376 \mathrm{~cm}^{-1}\right)$. An explanation for this, borne out by the crystallographic data, is that the $\mathrm{N}-\mathrm{H}$ group is sterically protected by the two thiophene rings and cannot undergo significant hydrogen-bonding [1] as can the less sterically hindered $\mathrm{N}-\mathrm{H}$ groups in dialkyl- and alkyl-arylimides [16, 25]. The weak bands just above $3000 \mathrm{~cm}^{-1}$ are associated with $\mathrm{C}-\mathrm{H}$ ring stretching [26]. All spectra of the metal complexes studied share other similarities with the free ligand such as the imide I, II, and III vibrations at 1642-1641, 1459-1456, and 1255-1253 $\mathrm{cm}^{-1}$ [25] and $\mathrm{ClO}_{4}^{-}$ vibrations at 1118,1074 , and $1045 \mathrm{~cm}^{-1}$ (Figure 4) [27] which indicate the presence of perchlorates in all of the metal complexes. The shift to lower frequency of the $\mathrm{C}=\mathrm{O}$ stretching vibrations (imide I) is consistent with oxygen binding to the metal ion. The imide II and III vibrations are made up of $\mathrm{v}_{\mathrm{as}}(\mathrm{C}-\mathrm{N}-\mathrm{C})$ and $\delta(\mathrm{N}-\mathrm{H})$; the first mode is weighted heavily in the imide II vibration while the reverse is true for imide III [16]. The imide II vibrations are lower than in the parent ligand while a shift to higher frequency of the imide III vibrations indicates that the six-membered ring arising from chelation results in delocalization of electron density which is supported by the bond lengths and bond angles between $\mathrm{C}(\mathrm{O}) \mathrm{N}(\mathrm{H}) \mathrm{C}(\mathrm{O})$ species (Table 3 ).

\section{(Insert Table 3 and Fig. 4 here)}

\subsection{Visible Spectroscopy}

Spectroscopic studies of the complexes of $\operatorname{di}\left(2\right.$-thienyl)imide $\left(3,4,10^{-2} \mathrm{M}\right)$ in the visible region were performed in HPLC grade methanol. The zinc (II) complex is colorless, and Mn (II) was too weak to observe. For 4 a broad absorbance band appeared near $512 \mathrm{~nm}$ consistent with known spectra of Co(II) complexes [28].

\section{Experimental}

\subsection{Materials and Equipment}

2-Thenoyl chloride, 2-thiophene carboxamide, potassium t-butoxide, potassium hydride, and anhydrous iron trichloride were purchased from ACROS Organics and used as received. Ethyl acetate, THF, dichloromethane, methanol, and acetone (all HPLC 
grade) were purchased from Fisher Scientific as was petroleum ether and ammonium peroxydisulfate. Ethanol was obtained from AAPER and triethylamine from SigmaAldrich. The hexahydrates of cobalt perchlorate, manganese perchlorate, and zinc perchlorate were obtained from Alfa Aesar.

Infrared spectra were obtained using a Perkin-Elmer Spectrum 100 ATR-FT-IR spectrophotometer equipped with a diamond anvil. NMR spectra were taken using Bruker Avance 300 and $500 \mathrm{MHz}$ instruments; chemical shifts are relative to TMS. GC/MS spectra were recorded on an Agilent 6850/5973 GC/MS system. Visible spectra were recorded on $10^{-2} \mathrm{M}$ samples (1 cm Starna quartz matched cells) on an HP Agilent 8453 Diode Array UV-Visible Spectrophotometer. Microwave irradiation was carried out in a GlassChem 20 Vessel using a CEM MARS Synthesis System. Elemental Analyses were carried out by Atlantic Microlabs, Inc. EIS measurements were carried out using a Gamry Instruments Series G 300 Potentiostat/Gavanostat/ZRA instrument; the sample disk was held between ITO-coated glass plates in a two-point probe arrangement.

Single crystal X-ray diffraction data were collected on a Bruker SMART APEX $\mathrm{CCD}$ area detection system at $193 \mathrm{~K}$ using MoK $\alpha$ radiation. Data were corrected for variable absorption effects using the multi-scan (SADABS) method [29]. All of the structures were solved by direct methods using the Bruker SHELXTL/XS [30] component of the APEX2 software suite [31] and refined using full-matrix least-squares methods with SHELXL-2014 [32]. Crystallographic data for 2, 3, and 4 have been deposited at the Cambridge Crystallographic Data Centre (Codes: 1494605-1494607). These data can be obtained free of charge via the internet at www.ccdc.cam.ac.uk/data_request/cif, by email at data_request@ccdc.cam.ac.uk., or by contacting the Cambridge Crystallographic Data Centre, 12 Union Road, Cambridge CB2 1EZ, UK; fax: +44(0)1223-336033. Analysis of the structure was carried out using PLATON [33] and Mercury 3.3 software [34].

\subsection{Synthesis}

\subsection{1 di(2-thienyl)imide}

\subsubsection{Acid catalyzed reaction}

2-Thenoyl chloride $(0.983 \mathrm{~g}, 6.71 \mathrm{mmol})$ was added to a flask containing thiophene-2-carboxamide $(1.00 \mathrm{~g}, 7.86 \mathrm{mmol})$ under argon. After adding 3 drops of sulfuric acid, the reaction mixture was stirred and heated to roughly $100^{\circ} \mathrm{C}$ for $24 \mathrm{hrs}$. The product mixture was a dark tar, and, in contrast to previous separations by flash chromatography, was directly sublimed in vacuum into a condenser held at $-78^{\circ} \mathrm{C}$ from which it was collected. The white crystalline product was verified as di(2-thienyl)imide by TLC against a genuine sample. The isolated yield was $12.4 \%$

\subsubsection{Base catalyzed reaction}

An earlier attempt at the synthesis of 1, employed potassium t-butoxide as a base to facilitate attack of 2-thenoyl chloride on the deprotonated amide but the yield was low 
(12\%) [1]. In the expectation that a stronger base would improve the yield, dry THF $(60 \mathrm{~mL})$ and 2-thiophenecarboxamide $(1.00 \mathrm{~g}, 7.86 \mathrm{mmol})$ were placed in a $250 \mathrm{~mL}$ flame-dried three-neck round-bottom flask, equipped with a condenser, under argon with stirring at $0^{\circ} \mathrm{C}$. Potassium hydride, which was washed four times with ether to remove mineral oil, was added to the solution slowly. The mixture was allowed to react for 30 minutes or until the solution stopped bubbling. A solution of thenoyl chloride $(0.840 \mathrm{~mL}$, $1.15 \mathrm{~g}, 7.84 \mathrm{mmol})$ in dry THF $(30 \mathrm{~mL})$ was added dropwise. The solution was allowed to warm to room temperature and stirred overnight. After the removal of THF, the brown product mixture was cooled, taken up in dichloromethane, and washed several times with sodium bicarbonate, brine, and water. The organic phases were dried with magnesium sulfate and rotary-evaporated to give a tan solid. The crude product was dissolved in a small amount of dichloromethane and was purified using flash chromatography (40:60 ethyl acetate / petroleum ether) resulting in a $13.4 \%$ yield.

\subsubsection{Microwave Method}

An alternative procedure gave improved results. A mixture of thiophene-2carboxamide $(0.500 \mathrm{~g}, 3.93 \mathrm{mmol})$, thenoyl chloride $(0.420 \mathrm{~g}, 2.86) \mathrm{mmol})$, and two drops of conc. sulfuric acid was added to a dry GlassChem 20 Vessel. The power level and irradiation time were optimized ( $350 \mathrm{~W}$ for $3 \mathrm{~min}$.). The cooled product mixture was quenched, extracted and purified by the protocols described above. The yield was $18.0 \%$.

\subsection{2 di(2-thienyl)imide complexes, $\mathbf{2}-\mathbf{4}$}

The synthesis of the complexes 2-4 is illustrated by the synthesis of bis(di(2thienyl)imide)manganese (II) perchlorate, 3. Manganese (II) perchlorate ( $3.0 \mathrm{mg}, 0.0083$ $\mathrm{mmol})$ was dissolved in warm ethyl acetate and ligand $1(4.0 \mathrm{mg}, 0.017 \mathrm{mmol})$ was dissolved in warm ethyl acetate in a separate vial. The solution of $\mathbf{1}$ was added to the manganese solution upon which small almost colorless crystals began to form. The sample was allowed to undergo digestion in a dark, vibration-free environment. Light pink crystals suitable for single-crystal X-ray analysis were obtained. Anal.: $\mathrm{Mn}\left(\mathrm{C}_{10} \mathrm{H}_{7} \mathrm{NO}_{2} \mathrm{~S}_{2}\right)_{2}\left(\mathrm{ClO}_{4}\right)_{2}$, 3. Calc'd. \% C, 33.00; H, 1.94. Found: C, 33.07; $\mathrm{H}$, 2.06.Yield: $60 \%$. Anal.: $\mathrm{Co}\left(\mathrm{C}_{10} \mathrm{H}_{7} \mathrm{NO}_{2} \mathrm{~S}_{2}\right)_{2}\left(\mathrm{ClO}_{4}\right)_{2}$, 4. Calc'd \%: C, 32.80; H, 1.93. Found: C, 31.24; $\mathrm{H}, 2.30$. Yield: $78 \%$. Visible spectrum (in methanol) $\lambda_{\max }(\mathrm{nm}): 512$. Anal.: $\mathrm{Zn}\left(\mathrm{C}_{10} \mathrm{H}_{7} \mathrm{NO}_{2} \mathrm{~S}_{2}\right)_{2}\left(\mathrm{H}_{2} \mathrm{O}\right)_{2}\left(\mathrm{ClO}_{4}\right)_{2}$, 2. Calc'd \% C, 31.00; H, 2.34. Found: $\mathrm{C}, 30.89$.; H, 2.25.Yield: $41 \%$. IR Spectra: Selected vibrations can be observed in Table 3 and the spectra in Fig. 4.

\subsection{3 poly(di(2-thienyl))imide)}

\subsubsection{Ammonium peroxydisulfate as oxidant}

An aqueous solution of ammonium peroxydisulfate $(0.707 \mathrm{~g})$ and di(2-thienyl)imide $(0.0705 \mathrm{~g}, 0.297 \mathrm{mmol})$ was stirred at $60^{\circ}$ for eight days during which the solution turned from yellow to blue to black and contained shiny black flecks. The solid was collected by vacuum filtration, washed, dried, and weighed $(0.0680 \mathrm{~g})$ giving a yield of $96 \%$ based on 
di(2-thienyl)imide. The infrared spectrum was consistent with polymer/oligomer formation based on comparison with the monomer. The product was compressed into a pellet using an infrared press. The relatively thick pellet $(90 \mu \mathrm{m})$ was sandwiched between two ITO-coated glass plates in a two point probe arrangement. EIS measurements indicated a conductivity of $3.6 \times 10^{-6} \mathrm{~S} \mathrm{~cm}^{-1}$.

\subsubsection{2 $\mathrm{FeCl}_{3}$ as oxidant}

A $0.60 \mathrm{M} \mathrm{FeCl}_{3}$ solution in chloroform $(3.39 \mathrm{~mL})$ was added to di(2-thienyl)imide $(0.115 \mathrm{~g}, 0.485 \mathrm{mmol})$ in chloroform. The solution was stirred under room temperature for over 8 hours during which it turned yellow but without formation of any polymer.

\section{Conclusions}

This work demonstrates that complex formation between neutral di(2thienyl)imide and transition metals Mn (II), Co (II), and Zn (II) occurs via coordination by carbonyl oxygen atoms resulting in two-ligand bidentate complexes. The crystal structures of Mn (II) and Co (II) are isostructural and have perchlorate ions present in the apical positions. The $\mathrm{Zn}$ (II) complex is quite different having two water molecules in the apical positions and the thiophene rings bent from the equatorial plane. This distortion from planarity results from multiple close intra- and intermolecular contacts for di(2thienyl)imide within and between 1D chains parallel to the $b$ axis and formed by strong hydrogen-bonding of the apical water molecules with pairs of perchlorate ions. Crystal structures of neutral bis(aryl)imide complexes bonded only through oxygen are quite rare.

Di(2-thienyl)imide was polymerized using ammonium peroxodisulfate, but a 90 $\mu \mathrm{m}$ pellet was of low conductivity. This work paves the way for an investigation of the possible ion-sensing and metal ion uptake/release properties of the polymer since it is clear that complexation and polymerization are feasible.

\section{Acknowledgements}

Support by the Camille and Henry Dreyfus Senior Scientist Mentor Program is gratefully acknowledged. The authors wish to thank Prof. Michael Gross, WFU, for help with the EIS measurements. The WFU X-ray Facility thanks the National Science Foundation (grant CHE-0234489) for funds to purchase the X-ray instrument and computers.

\section{References}

1. C. M. MacNeill, J. Dai, C. S. Day, S. P. Lazar, S. J. Howell, R. E. Noftle, Synth. Metals. 159 (2009) $1628-1635$.

2. T.-P Huynh, P. S. Sharma, M. Sosnowska, F. D. Souza, W. Kutner, Prog. Polymer Sci. (2015) http//dx.doi.org/10.1016/j.prog.polymsci 2015.04.org.

3. D. T. McQuade, A. E. Pullen, T. M. Swager, Chem. Rev. 100 ( 2000) 2537-2574.

4. C. Friebe, J. Görls, M. Jäger, U. S. Schubert, Eur. J. Inorg. Chem. (2013), 4191-4202. 
5. J. Kieffer, B. Divisia-Blohorn, G. Bidan, C. Schaffner-Hamann, J.-M. Kern, J.-P. Sauvage, Comptes Rendus Chemie, 10 (2007) 1224-1232.

6. S. Zhu, T. Swager, J. Am. Chem. Soc. 119 (1997) 12568-12577.

7. B. Fabre, E. Hao, Z. M. LeJeune, E. K. Amuhaya, F. Barriere, J. C. Garno, M. G. H Vicente, Appl. Mater. \& Interfac. 2 (2010) 691-702.

8. A. Jaafari, V. Ouzeau, M. Ely, F. Rodriguez, K. Chane-Ching, A. Yassar, J. J. Aaron, Synth. Metals. 147 (2004) 183-189.

9. X. Li, C. Zhao, Y. Wang, J. Yao, Chem. Commun. (2008) 2444-2446.

10. X. Li, Y. Fang, P. Deng, J. Hu, T. Li, W. Feng, L. Yuan, Org. Lett. 13 (2011) 4628-4631.

11. (a.) R. Agneeswari, I. Shin, V. Tamilavan, D. Y. Lee, S. Cho, Y. in, S. H. Park, M. H. Hyun, New J.

Chem. 3 (2015) 4658-4669. (b.) H. J. Kirner, E. Martin, P. Bojard, J. C. Flores, J. T. Kopping, PCT Int.

Appl, 2014. WO 2014180704 A1 20141113. (c.) W. Li, C. Ge, F. Zhao, C. Mei, L. Liang, Y. Xie, Faming

Zhuanli Shenqing, 2014 CN 103739829 A 20140423. (d.) W. A. Braunecker, Z. R. Owczarczyk, A. Garcia, N. Kopidakis, R. E. Larsen, S. R. Hammond, D. S. Ginley, D. C. Olsen, Chem. Mater. 24 (2012) 13461356.

12. (a.) Y. Şahin, B. Ercan, M. Şahin, Talanta, 75 (2008) 369-375. (b.) U. Tamer, N. Ertas, Y. A. Udum, Y. Şahin, K. Pekmez, A. Yaldiz, Talanta 67 (2005) 245-251. (c.) U. Tamer, Y. Şahin, N. Ertas, Y. Udum, K.

Pekmez, J. Electroanal. Chem. 570 (2004) 6-12.

13. M. Hepel, Z. Xingmin, R. Stephenson, S. Perkins, Microchemical Journal. 56 (1997) 79-92.

14. (a) J. F. J. Dippy, V. Moss, J. Chem. Soc. (1952) 2205. (b) H. Ley; F. Werner, Ber. (1913) 4040. (c) M. Raban, R. A. Keintz, E. A. Noe, Tetrahedron Lett. 19 (1979) 1633-1636. (d) P. S. Gentile, J. White, S.

Haddad, Inorg. Chim. Acta. 13 (1975) 149-161. (e) P. S. Gentile, T. A. Shankoff, J. Inorg. Nucl. Chem. 27 (1963), 2301-2309.

15. M. Goodgame, I. Hussain, Inorg. Chim. Acta. 229 (1995) 165-169.

16. K. S. Kraihanzel, S. C. Grenda, Inorg. Chem. 4 (1965) 1037-1042.

17. K. E. Gubina, V. A. Ovchynnikov, V. M. Amirkhanov, H. Fischer, R. Stumpf, V. V. Skopenko, Z. Naturforsch. B. Chem. Sci., 55 (2000) 576-582.

18. R. C. Garcia, K. Patel, C. S. Day, R. E. Noftle, Abst. SE Reg. Am. Chem. Soc. Raleigh, NC. Nov. 1417, 2012. SERM 808.

19. L. Beyer, F. Dietze, P. Schreibler, R. Szargan, E. Hoyer, Z. anorg. allg. Chem. 434 (1977) 16-28.

20. A. Kamiyama, T. Noguchi, T. Kajiwara, T. Ito, Inorg. Chem. 2002, 41, 507-512.

T. Kajiwara, R. Sensui, T. Noguchi, A. Kamiyama, T. Ito, Inorg. Chim. Acta. 337 (2002) 299-307.

21. J. Lee, M. Hong, Y. Jung, E. J. Cho, H. Rhee, Tetrahedron. 68( 2012) 2045-2051.

22. Z. S. Zhao, P. G. Pickup, J. Electroanal. Chem. 404 (1996) 55-60.

23. B. H. Patil, S. J. Patil, C. D. Lokhande, Electroanalysis. 26 (2014) 2023-2032. U. Male, B. S. Singu, P. Srinavasan, J. Appl. Polymer Sci. 132 (2015) 42012/1-42012/12. B. Lee, V. Shashadri, G. A. Sotzing, Langmuir. 21 (2005) 10797-10802.

24. A. Bondi, J. Phys. Chem. 68 (1964) 441-451. R. S. Rowland, R. Taylor, ibid. 100 (1996), 7384-7391.

25. V. Bertolasi, P. Gilli, V. Ferretti, G. Gilli, Acta Cryst. B51 (1995) 1004-1015.

V. Mizrahi, M. L. Niven, S. Afr. J. Chem. 36 (1983) 137-142.

25. J. Dai, C. S. Day, R. E. Noftle, Tetrahedron. 59 (2003) 9389-9397.

26. D. L. Pavia, G. M. Lampman, G. S. Kriz, Introduction to Spectroscopy, $2^{\text {nd }}$ Ed. Saunders, New York, 1996.

27. K. Nakamoto, Infrared and Raman Spectra of Inorganic and Coordination Compounds,

Wiley, New York, 1986, Pt. III, 251-253.

28. R. Abu-Eittah, G. J. Arafa, Inorg. Nucl. Chem. 32 (1970) 2721-2729.

29. L. Krause, R. Herbst-Irmer, G. M. Sheldrick, D. Stalke, J. Appl. Cryst. 48 (2015) 3-10.

30. G. M. Sheldrick, Acta Cryst. A64 (2008) 112-122.

31. Bruker (2013). APEX2 (Version 2013.4-1). Bruker AXS Inc., Madison, Wisconsin, USA.

32 G. M. Sheldrick, Acta Cryst. C71 (2015) 3-8.

33.A. L. Spek, Acta Cryst. D65 (2009) 148-155.

34. C. F. Macrae, I. J. Bruno, J. A. Chisholm, P. R. Edgington, P. McCabe, E. Pidcock, L. Rodriguez-

Monge, R. Taylor, J. van de Streek, P. A. Wood, J. Appl. Crystallogr. 41 (2008) 466-470. 


\section{Captions for: Schemes Figures and Tables}

Scheme 1. Metal uptake and release by complexes upon an applied electrochemical potential shown for $\mathbf{2}$. (3 and $\mathbf{4}$ would have perchlorates in apical positions. In reality no more than one in four thiophene rings would be oxidized).

Scheme 2. Synthesis of ligand and polymer.

Figure 1. Structure of 2. (a.) Atomic displacement plot (probability level 50\%) with the atom labeling scheme of 2. (b.) Packing diagram of 2 viewed in projection along the $a$ axis showing hydrogen-bonding involving the water molecules.

Figure 2. Structure of 3. (a.) Atomic displacement plot (probability level 50\%) with the atom labeling scheme of $\mathbf{3}$ (b.) Mercury drawing of $\mathbf{3}$ showing shortest non-bonded contacts involving perchlorate.

Figure 3. Packing diagram of $\mathbf{3}$ (along $b$ axis).

Figure 4. Infrared spectra of the metal complexes. Spectra top to bottom are $\mathrm{C}_{10} \mathrm{H}_{7} \mathrm{NO}_{2} \mathrm{~S}_{2}, \mathrm{Co}\left(\mathrm{C}_{10} \mathrm{H}_{7} \mathrm{NO}_{2} \mathrm{~S}_{2}\right)_{2}\left(\mathrm{ClO}_{4}\right)_{2}$, $\left[\mathrm{Zn}\left(\mathrm{C}_{10} \mathrm{H}_{7} \mathrm{NO}_{2} \mathrm{~S}_{2}\right)_{2}\left(\mathrm{H}_{2} \mathrm{O}\right)_{2}\right]\left(\mathrm{ClO}_{4}\right)_{2}$, and $\mathrm{Mn}\left(\mathrm{C}_{10} \mathrm{H}_{7} \mathrm{NO}_{2} \mathrm{~S}_{2}\right)_{2}\left(\mathrm{ClO}_{4}\right)_{2}$ respectively.

(table captions are already in tables)

Table 1. Summary of crystal data and structure refinements for (2)-(4).

Table 2. Selected bond lengths, contacts, and bond angles for $\mathbf{2 , 3}$, and $\mathbf{4}$.

Table 3. Infrared spectra: selected frequencies of the ligand and metal complexes 2-4. 
Table 1

Summary of crystal data and structure refinements for (2)-(4)

\begin{tabular}{|c|c|c|c|}
\hline Compound & 2 & 3 & 4 \\
\hline Empirical formula & $\mathrm{C}_{20} \mathrm{H}_{18} \mathrm{Cl}_{2} \mathrm{~N}_{2} \mathrm{O}_{14} \mathrm{~S}_{4} \mathrm{Zn}$ & $\mathrm{C}_{20} \mathrm{H}_{14} \mathrm{Cl}_{2} \mathrm{MnN}_{2} \mathrm{O}_{12} \mathrm{~S}_{4}$ & $\mathrm{C}_{20} \mathrm{H}_{14} \mathrm{Cl}_{2} \mathrm{CoN}_{2} \mathrm{O}_{12} \mathrm{~S}_{4}$ \\
\hline Formula weight & 774.87 & 728.41 & 732.40 \\
\hline Temperature (K) & 193 & 193 & 193 \\
\hline Crystal system & monoclinic & monoclinic & monoclinic \\
\hline Space group & $C 2 / c$ & $P 2_{1} / c$ & $P 2_{1} / c$ \\
\hline \multicolumn{4}{|l|}{ Unit cell dimensions } \\
\hline$a(\AA)$ & $19.4483(17)$ & $8.5306(8)$ & $8.5792(5)$ \\
\hline$b(\AA)$ & $7.9071(7)$ & $9.4634(8)$ & $9.2504(6)$ \\
\hline$c(\AA)$ & $19.8739(17)$ & $16.8307(15)$ & $16.8369(10)$ \\
\hline$\beta\left(^{\circ}\right)$ & $109.348(1)$ & $103.488(1)$ & $102.664(1)$ \\
\hline Volume $(\AA)^{3}$ & $2883.6(4)$ & $1321.2(2)$ & $1303.69(14)$ \\
\hline $\mathrm{Z}$ & 4 & 2 & 2 \\
\hline Calcd. density $\left(\mathrm{Mg} \mathrm{m}^{-3}\right)$ & 1.785 & 1.831 & 1.866 \\
\hline Absorption Coeff. $\left(\mathrm{mm}^{-1}\right)$ & 1.40 & 1.09 & 1.25 \\
\hline $\mathrm{F}(000)$ & 1568 & 734 & 738 \\
\hline Crystal size (mm) & $0.19 \times 0.09 \times 0.08$ & $0.32 \times 0.13 \times 0.09$ & $0.40 \times 0.11 \times 0.11$ \\
\hline Theta range $\left(^{\circ}\right)$ & $3.8-30.5$ & $3.7-30.0$ & $3.7-30.1$ \\
\hline \multirow[t]{3}{*}{ Limiting indices } & $h=-27 \rightarrow 27$ & $h=-11 \rightarrow 11$ & $h=-12 \rightarrow 12$ \\
\hline & $k=-11 \rightarrow 11$ & $k=-13 \rightarrow 13$ & $k=-13 \rightarrow 13$ \\
\hline & $l=-27 \rightarrow 27$ & $l=-23 \rightarrow 23$ & $l=-23 \rightarrow 23$ \\
\hline Reflections (independent) & 4193 & 3851 & 3815 \\
\hline $\mathrm{R}_{\mathrm{int}}$ & 0.033 & 0.033 & 0.031 \\
\hline $\begin{array}{l}\text { Absorption Correction } \\
\text { transmission range }\end{array}$ & $0.655-0.746$ & $0.723-0.909$ & $0.621-0.746$ \\
\hline Data/parameters & $4193 / 208$ & $3851 / 191$ & $3815 / 191$ \\
\hline Goodness-of-fit on $\mathrm{F}^{2}$ & 1.04 & 1.03 & 1.06 \\
\hline \multicolumn{4}{|l|}{ Final $\mathrm{R}$ indices } \\
\hline$\left[\mathrm{F}_{0}>4 \sigma\left(\mathrm{F}_{0}\right)\right.$ data $]$ & $\mathrm{R}_{1}=0.035$ & $\mathrm{R}_{1}=0.036$ & $\mathrm{R}_{1}=0.031$ \\
\hline & $\mathrm{wR}_{2}=0.093$ & $\mathrm{wR}_{2}=0.098$ & $\mathrm{wR}_{2}=0.086$ \\
\hline $\begin{array}{l}\text { Largest differential } \\
\text { peak and hole }\left(\mathrm{e}^{-} / \AA^{3}\right)\end{array}$ & $0.555,-0.429$ & $0.756,-0.388$ & $0.752,-0.449$ \\
\hline
\end{tabular}

$\mathrm{R}_{1}=\Sigma|| \mathrm{F}_{\mathrm{o}}|-| \mathrm{F}_{\mathrm{c}}|| / \Sigma\left|\mathrm{F}_{\mathrm{o}}\right|$.

$\mathrm{wR}_{2}=\left\{\Sigma\left[\mathrm{w}\left(\mathrm{F}_{\mathrm{o}}^{2}-\mathrm{F}_{\mathrm{c}}^{2}\right)^{2}\right] / \Sigma\left[\mathrm{w}\left(\mathrm{F}_{\mathrm{o}}^{2}\right)^{2}\right]\right\}^{1 / 2}$.

Goof $=\left[\Sigma \mathrm{w}\left(\mathrm{F}_{\mathrm{o}}^{2}-\mathrm{F}_{\mathrm{c}}^{2}\right)^{2} /\left(\mathrm{N}_{\mathrm{d}}-\mathrm{N}_{\mathrm{p}}\right)\right]^{1 / 2}$.

$\mathrm{R}_{\text {int }}=\Sigma \mid \mathrm{F}_{\mathrm{o}}^{2}-\mathrm{F}_{\mathrm{o}}^{2}$ (mean) $\mid / \Sigma \mathrm{F}_{\mathrm{o}}^{2}$. 
Table 2

Selected bond lengths, contacts, and bond angles for $\mathbf{2 , 3}$, and $\mathbf{4}$.

\begin{tabular}{lllr}
\hline Compound & \multicolumn{1}{c}{$\mathbf{2}$} & \multicolumn{1}{c}{$\mathbf{3}$} & $\mathbf{4}$ \\
\hline Formula & $\mathrm{C}_{20} \mathrm{H}_{18} \mathrm{Cl}_{2} \mathrm{~N}_{2} \mathrm{O}_{14} \mathrm{~S}_{4} \mathrm{Zn}$ & $\mathrm{C}_{20} \mathrm{H}_{14} \mathrm{Cl}_{2} \mathrm{~N}_{2} \mathrm{O}_{12} \mathrm{~S}_{4} \mathrm{Mn}$ & $\mathrm{C}_{20} \mathrm{H}_{14} \mathrm{Cl}_{2} \mathrm{~N}_{2}$ \\
& & & \\
Bond lengths $(\AA)$ & & & \\
& & & \\
$\mathrm{M} 1-\mathrm{O} 1$ & $2.090(1)$ & $2.117(1)$ & $2.017(1)$ \\
$\mathrm{M} 1-\mathrm{O} 2$ & $2.055(1)$ & $2.139(1)$ & $2.039(1)$ \\
$\mathrm{M} 1-\mathrm{O} 3$ & & $2.312(1)$ & $2.168(1)$ \\
$\mathrm{O} 1-\mathrm{C} 1$ & $1.236(2)$ & $1.235(2)$ & $1.235(2)$ \\
$\mathrm{O} 2-\mathrm{C} 2$ & $1.234(2)$ & $1.235(2)$ & $1.234(2)$ \\
$\mathrm{N} 1-\mathrm{C} 1$ & $1.381(3)$ & $1.375(2)$ & $1.373(2)$ \\
$\mathrm{N} 1-\mathrm{C} 2$ & $1.375(3)$ & $1.380(2)$ & $1.382(2)$ \\
$\mathrm{C} 1-\mathrm{C} 3$ & $1.448(3)$ & $1.451(2)$ & $1.449(2)$ \\
$\mathrm{C} 2-\mathrm{C} 7$ & $1.452(3)$ & $1.448(2)$ & $1.449(2)$ \\
$\mathrm{C} 3-\mathrm{S} 1$ & $1.715(2)$ & $1.716(2)$ & $1.722(2)$ \\
$\mathrm{C} 7-\mathrm{S} 2$ & $1.716(2)$ & $1.723(2)$ &
\end{tabular}

Hydrogen bonding and short contacts $(\AA)$

$\begin{array}{ll}\mathrm{O} 7-\mathrm{H} \cdots \mathrm{O} 4 & 2.794(2) \\ \mathrm{O} 8-\mathrm{H} \cdots \mathrm{O} 3^{\text {ii }} & 2.767(2) \\ \mathrm{H} 5 \cdots \mathrm{S} 2^{\text {iv }} & 2.91(-) \\ \mathrm{H} 9 \cdots \mathrm{S} 1^{\text {iii }} & 2.81(-) \\ \mathrm{N} 1-\mathrm{H} \cdots \mathrm{O} p^{\text {ii }} & \\ \mathrm{C} 2 \cdots \mathrm{Ox} & \\ \mathrm{O} 2 \cdots \mathrm{Ox} & \end{array}$

$3.301(2)$ $3.076(2)$ $3.092(2)$

$80.63(5)$

$99.37(5)$

$180.0(-)$

$122.9(2)$

$122.5(2)$

$116.5(2)$

$116.3(2)$
$3.242(2)$

$3.032(3)$

$3.045(2)$

Bond angles $\left(^{\circ}\right)$

$\begin{array}{ll}\mathrm{O} 1-\mathrm{M}-\mathrm{O} 2^{\mathrm{i}} & 96.02(5) \\ \mathrm{O} 3-\mathrm{M}-\mathrm{O} 3^{\mathrm{i}} & \\ \mathrm{O} 8-\mathrm{M}-\mathrm{O} 7 & 180.0(-) \\ \mathrm{O} 1-\mathrm{C} 1-\mathrm{N} 1 & 122.4(2) \\ \mathrm{O} 2-\mathrm{C} 2-\mathrm{N} 1 & 123.0(2) \\ \mathrm{N} 1-\mathrm{C} 1-\mathrm{C} 3 & 115.5(2) \\ \mathrm{N} 1-\mathrm{C} 2-\mathrm{C} 7 & 115.6(2)\end{array}$

$85.13(4)$

$94.87(4)$

$180.0(-)$

$123.0(1)$

$122.5(1)$

$116.8(2)$

$116.4(1)$

Hydrogen bond angles $\left(^{\circ}\right)$

$\begin{array}{ll}\mathrm{O} 7-\mathrm{H} \cdots \mathrm{O} 4 & 173(3)^{\mathrm{o}} \\ \mathrm{O} 8-\mathrm{H} \cdots \mathrm{O} 3^{\mathrm{ii}} & 169(3)^{\mathrm{o}} \\ \mathrm{C} 5-\mathrm{H} \cdots \mathrm{S} 2^{\text {iv }} & 170(-)^{\mathrm{o}} \\ \mathrm{C} 9-\mathrm{H} \cdots \mathrm{S} 1^{\mathrm{iii}} & 165(-)^{\mathrm{O}} \\ \mathrm{N} 1-\mathrm{H} \cdots \mathrm{O} 4^{\text {ii }} & \end{array}$

Symmetry codes:

Compound 2 (i) $-x+1, y,-z+1 / 2$; (ii) $x, y+1, z$; (iii) $\mathrm{x},-\mathrm{y}+1, \mathrm{z}+1 / 2$; (iv) $\mathrm{x}+1 / 2, \mathrm{y}-1 / 2, \mathrm{z}$;

Compound 3 (i) $-x,-y,-z$; (ii) $-x,-y+1,-z$;

Compound 4 (i) $-x,-y,-z$; (ii) $x, y+1, z$.

For compound $\mathbf{3}$ and 4, Op represents perchlorate oxygens, O4 and O6, respectively; Ox represents perchlorate oxygens, $\mathrm{O} 6$ and $\mathrm{O} 5$, respectively. 
Table 3

\begin{tabular}{lcccc}
\hline Infrared spectra: Selected frequencies of the ligand and metal complexes 2-4. \\
\hline Assignments & $\mathbf{1}$ & $\mathbf{2}$ & $\mathbf{3}$ & $\mathbf{4}$ \\
$\mathrm{N}-\mathrm{H}$ & $3419 \mathrm{~s}$ & $3405 \mathrm{~m}$ & $3376 \mathrm{~m}$ & $3409 \mathrm{~m}$ \\
$\mathrm{C}-\mathrm{H}$ (ring) & $3076 \mathrm{~s}$ & $3101 \mathrm{w}$ & $3102 \mathrm{w}$ & $3103 \mathrm{w}$ \\
Imide I (a, s) & $1705 \mathrm{~s}, 1667 \mathrm{~m} 1642 \mathrm{sh}$ & $1631 \mathrm{~s}, \mathrm{sh}$ & $1642 \mathrm{~s}, \mathrm{sh}$ \\
Imide II & $1519 \mathrm{~s}$ & $1459 \mathrm{~s}$ & $1459 \mathrm{~s}$ & $1456 \mathrm{~s}$ \\
Imide III & $1216 \mathrm{~s}$ & $1254 \mathrm{~s}$ & $1255 \mathrm{~s}$ & $1253 \mathrm{~s}$ \\
$\mathrm{Cl}-\mathrm{O}\left(\mathrm{ClO}_{4}\right)$ & & $1121 \mathrm{~s}$ & $1116 \mathrm{~s}$ & $1118 \mathrm{~s}$ \\
& & $1070 \mathrm{~s}$ & $1074 \mathrm{~s}$ & $1067 \mathrm{~s}$ \\
& & $1038 \mathrm{~s}$ & $1033 \mathrm{~s}$ & $1041 \mathrm{~s}$
\end{tabular}


(fig. 1)

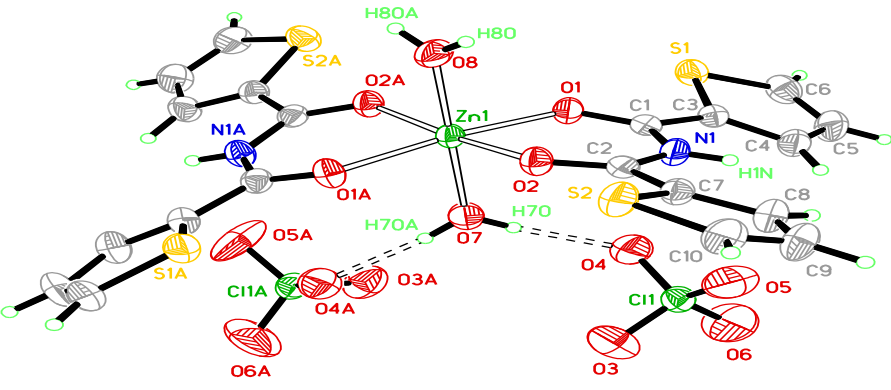

a

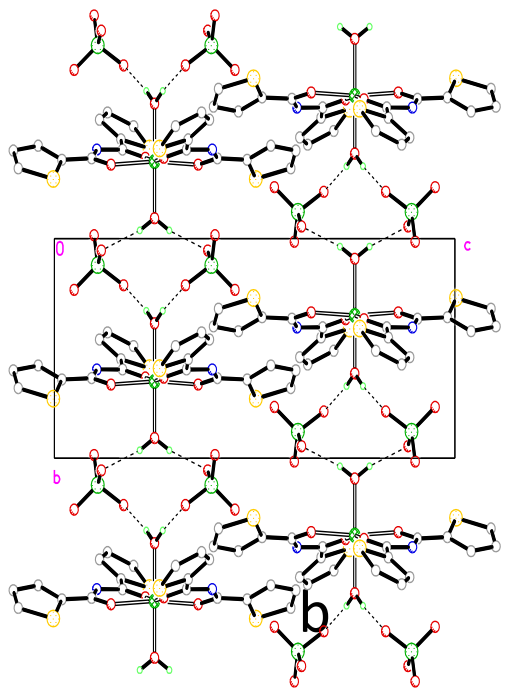


(fig. 2)

(fig. 3)

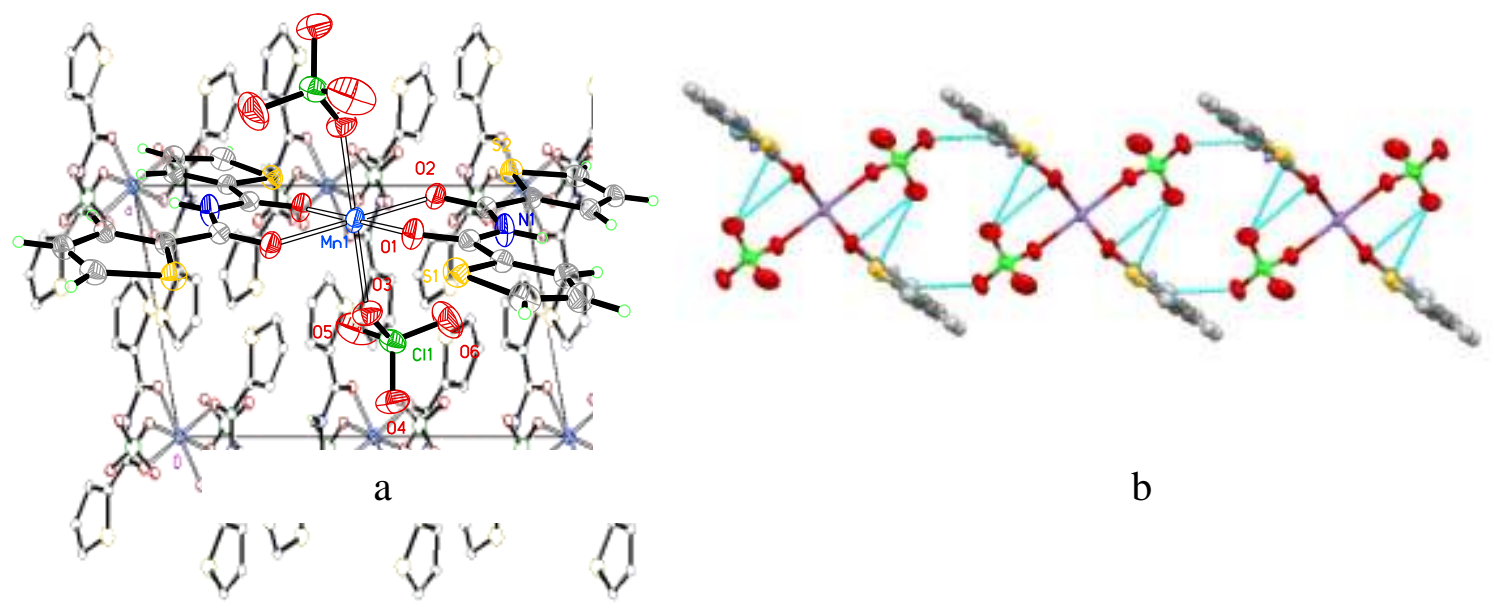


(fig. 4)

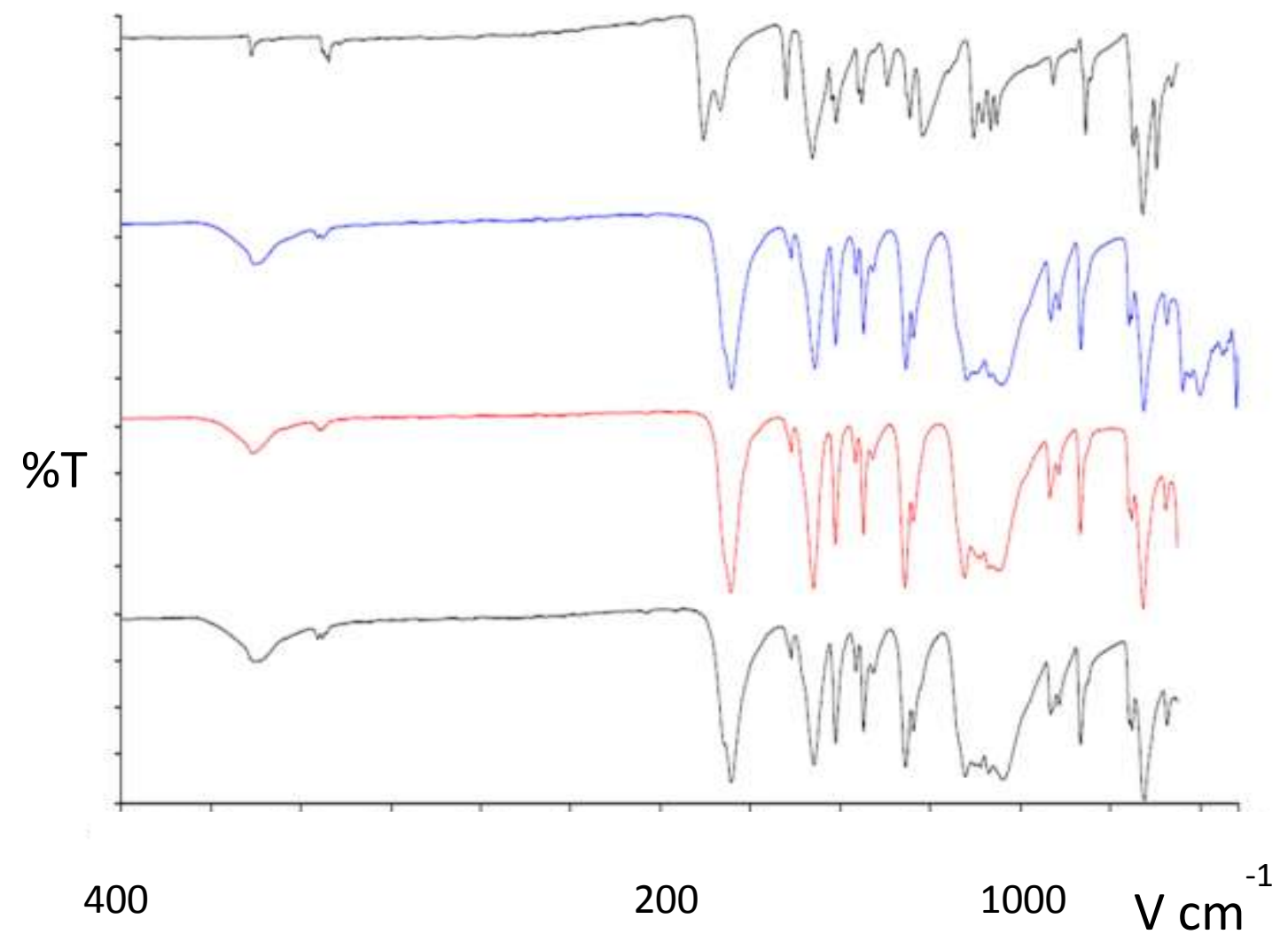

